\title{
With Special Consideration of Diagnosis
}

\author{
D. J. SALFIELD, M.D., B.Sc., D.P.M. \\ Consultant Psychiatrist, Winterton Hospital, Stockton and Thornaby Hospital and Stockton Child Guidance Clinic
}

\section{Clarification of the Concept of Schizophrenia}

This is not only of formal importance, but an essential for diagnosis, the institution of treatment, and the formulation of a correct prognosis. If schizophrenia is not distinguished from mimicking conditions, treatment rests on a purely empirical basis and remains precarious and uncontrolled. The recognition of the disease must be based on the forms it can take and especially on the phase in which it is. If this phase be an early one, the diagnosis is all too often missed.

Kraepelin thought that 'dementia praecox' was a degenerative brain disease or a metabolic disturbance producing auto-intoxication. This line of thought is still being pursued with contradictory and doubtful results. (See paragraph on pathology.) According to him, it manifests itself in loss of harmony between emotion, volition and intellect. And he states that the different forms are different expressions of a disease entity.

Bleuler taught that schizophrenia was an organic process, toxic or causative of structural changes, which made the break-up of the personality into several 'sub-personalities' possible. He thought in terms of syndromes forming subgroups, and he felt schizophrenia was not a disease entity. He distinguished three basic processes: (I) Disturbance of the association of ideas; (2) disturbance of affectivity, from which stemmed disorder of perception, orientation, memory, reality, will and attention; the primary symptoms. Secondary symptoms are: illusions, delusions, stupor, negativism, mannerisms, automatisms, impulsive actions and confusion; (3) disturbance of relationship with the external world.

Freud considered schizophrenia to be a regression to pre-genital stages of development, but he left the door to an ultimately organic substratum open.

Jung thinks of schizophrenia as a breaking up of the ego and flooding of its weak structure by contents of the collective unconscious, i.e. archetypal contents. This is supported by the experimentally produceable psychoses which resemble schizophrenia.
Mayer-Gross (1952) states that 'it is generally $\stackrel{\vec{\circ}}{-}$ agreed among clinicians that the concept of $\vec{\omega}$ schizophrenia as used in psychiatry based on certain characteristic symptoms probably com-co prises several disease entities of different aetiology. Attempts to break up this large grouping have 0 been made before and have failed. ... While $\underset{\omega}{\omega}$ we can only too willingly assent to this, there is a common denominator to all these schizophrenic $\omega$ disorders, exactly that one which has caused all $\overrightarrow{ }$ of them to be subsumed under this name.

\section{Description of the Traditional Forms}

I. Simple schizophrenia is characterized by an $\vec{\theta}$ early onset, about puberty, gradual developmenf of affective dulness and intellectual deterioration progressing to dementia. This process is at time arrested. Negativism, mannerisms, delusions and hallucinations are sometimes present.' Remissions are rarely complete and are, on the whole, infrequent. Often cases are difficult to differentiate from mental defect in the sbsence of a history. $\overrightarrow{\vec{O}}$ These patients may suggest organic states, but 3 no signs are found for this on examination.

2. In hebephrenic schizophrenia hallucinations are much more frequent, mainly auditory and $\frac{\partial}{3}$ cutaneous, listlessness, shallowness and inappropriateness of affect, i.e. silliness, laughing when they should cry and vice versa. Delusions are prominent and are often sexual and religious. Mannerisms and grimaces are frequent, as well as rambling ideation and inconsequential behaviour. Remissions are less infrequent than in the simple $\frac{D}{0}$ type, but scarring of the personality progresses with each attack and is permanent. Finally o dementia supervenes and leaves the patient an $N$ emotional and intellectual ruin. Suicide is not uncommon.

3. Katatonic schizophrenia is charzcterized by negativism, verbigeration, excitement and stupor with waxy flexibility. Delusions and hallucinations $\stackrel{\Phi}{\Phi}$ may be present. Violence and destructiveness are common. Patients in katatonic excitement may, as long as the furor lasts, be indistinguishable 
from acute manias. Remissions are frequent, and scarring less marked.

4. Paranoid schizophrenia features prominently delusions of a persecutory kind and hallucinations are present. The content of either is varying and they are fleeting and new trends appear. The onset is later; at the age of 30 or older. The endresult is hardly different, but remissions or arrest of the process is not rare, especially the latter.

5. Paraphrenia shows a lesser prominence of hallucinations, delusions are more fixed and show less individual variety, the personality remains relatively preserved, but finally also these patients deteriorate, the end result being a less marked state of dilapidation of the total personality.

6. Paranoia in its true form is very rare. There is little, if any, deterioration of the personality and hallucinations are rare. There is a constant, systematized edifice of delusional content, which, based on false premises, is internally logical and well organized. Often it arises on the basis of a real grievance or injustice. But moodiness, sensitiveness and shyness are often prominent, sometimes superseded by combativeness and litigiousness.

The last three forms are often subsumed under paranoid psychoses. Our impression is that they are psychogenetic, whilst the first three are largely somatically conditioned. But this is pure speculation on appearances. All forms, especially the first four, can be observed to lead over one into another, and mixed states are by no means rare, when we have to label: predominantly this or that.

Some forms, rarer than the preceding, exist in which other symptoms are prominent, e.g. dreamy states, depression and confusion. Depersonalization and dereization are common in all forms, as in other psychiatric states like depressions, neuroses and organic states such as tumours of the brain, concussions, etc. When obsessional features are marked, it has been claimed, dilapidation is in the end much less common.

Various other forms have been described as 'special' forms of schizophrenia. It is well known that anxiety, phobias, obsessions and compulsions, depression, etc., can mask schizophrenia. That one cannot make up one's mind whether schizophrenic or depressive symptoms predominate; whether symptoms are based on an underlying dementia, infective or organic process, e.g. injury, childbirth, etc., or whether we are dealing with a Pfropf-schizophrenia, i.e. superimposed on a degree of mental defect. This is a point to be considered in the differential diagnosis and does not need to lead to the establishment of 'special' forms. We believe we can always in the course of time decide whether we are confronted with 'schizophrenia.' If I am right, those doubts are academic and do not warrant special or even ' pseudo' categories (Pious, 1950). Such cases in point are, for instance

I. Oneirophrenia-characterized by disturb- $\stackrel{\unrhd}{\varrho}$

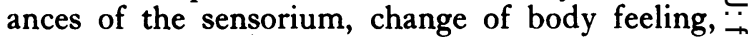
dreamlike and confusional states and deliroid states, described by Meduna and McCulloch(1945) - similar though not identical probably to 듬 Mayer-Gross' oneiroid states. This has been $\overline{\overline{\bar{N}}}$. misunderstood by some as ' pseudo-schizophrenia,' $\mathbb{\Phi}$ schizophrenic reaction, etc., as opposed to true schizophrenia. Such states occur in schizophrenia ${ }^{\infty}$ and probably in other conditions, in this way $\vec{\circ}$ similar to depersonalization phenomena. We $\vec{A}$ think Meduna has been misinterpreted, if such a ${ }_{\sigma}$ meaning is attributed.

2. Schizoidia-social relations recede in im- $\frac{0}{3}$ portance to the individual, hostility and loss of contact with his fellow men arise together with disharmony in relations, including sexual; opposition to family develops, an unstable work record $\omega$ and regression to mysticism have been described.

3. A category of chronic incipient schizophrenia has been described by Mace et al. (1949), differing from 'true' schizophrenia by the presence of $c$ numerous psychoneurotic symptoms, fair personality preservation, insight and easily missed partial loss of affect, thought disorder evident through superficial and shallow conversation, the syndrome being little subject to change. This $\frac{\overline{\overline{\omega s}}}{\mathrm{~s}}$. remindful of the discredited concept of 'pres psychosis,' and the cases in question may have remained undiagnosed. How a differential diagnosis excluding some psychoneurosis, slight degree $\stackrel{\mathbb{Q}}{\mathbb{2}}$ of dementia or mental defect, depression, etc., was $\overrightarrow{\vec{A}}$ arrived at is less comprehensible than the positive $\frac{3}{3}$ diagnosis.

4. Pseudo-neurotic schizophrenia, described byo Hoch and Polatin (1949) and alluded to frequently afterwards, includes 'pan-anxiety' and 'pan- $\underline{3}$. neurosis,' with all manner of ' neurotic ' symptoms. Catathymic thinking, condensation, concept displacement, vague contradictoriness, etc., are $ᄋ$ present. In spite of long discussion it remains unclear in what way they are special cases. They 을 appear frankly schizophrenic. Pan-anxiety states $\square$ are by no means rare in schizophrenics. The only을. point seems to be that some are described as displaying no 'gross thought disorder.' Slight degrees are quite sufficient to leave the diagnosis $\mathbb{O}$ intact.

5. Zaidens (1950) has described a dermatologic 0 hypochondriasis as a form of schizophrenia. $\operatorname{In}_{\bullet}$ this, a skin condition, usually acne vulgaris, or too $\frac{}{\Phi}$ scanty or plentiful growth of hair, was the com- $\stackrel{?}{?}$ plaint. The author thinks this to be similar to 0 the 'pseudo-neurotic' forms. The question again ${ }^{\circ}$ arises here is this a schizophrenia or not? We 
have come across numerous cases of 'monosymptomatic' schizophrenics within the last two years; two patients thinking their hair was falling out, and three patients with intractable and non-organic pain in the rectal and genital areas. We did not feel they could be included in a new form of schizophrenia, but we had to diagnose whether or not they were schizophrenics.

\section{Physical Signs}

Loss of weight, insomnia, malaise, irritability, often usher in the disease. Endocrine disorders, thyroid dysfunction and hirsuties are occasionally seen. Brown grey discs were found in 69 per cent. of 323 schizophrenics. Clumsiness, cyanosis and oedema of extremities are frequent in chronic patients who move little.

\section{Pathology}

Biopsy has shown swelling of oligodendroglia, cortical neuronic degeneration, proliferation of astrocytes and abnormal quantities of nucleotides. Macroscopic frontal lobe atrophy has been seen, also circulatory aplasia in general, low B.P., reduced blood volume, acrocyanosis, immature capillary patterns, gonadal atrophy, impaired liver function and nitrogen retention. (the latter in catatonia). Carbonic anhydrase was found uniformly distributed over cortex, whilst normally it is highly concentrated over the occipital and lowly over temporal area. Lessened lymphocytopenic response and 17-ketosteroid excretion under stress and subnormal ACTH response, perhaps due to a defect of communication between higher centres and endocrines, have been observed.

\section{Experimental Pathology}

Katatonia has been induced by bulbocapnine and neurotropic toxin derived from intestinal $E$. Coli from mental patients. Schizophrenia-like reactions have followed exhibition of atebrine, amphetamine and iso-nicotinic acid hydrazide. Schizophrenia-like states have been experimentally produced by lysergic acid and mescaline. It has been suggested that a lysergic acid-like substance is produced by faulty adrenalin metabolism.

\section{Psychopathology}

In addition to what has been already said, a few suggestions of interest may be mentioned here:

I. If the life situation becomes too threatening and difficult, schizophrenic withdrawal may be said to have survival value. Retiring into imagination the patient provides for himself the necessary surroundings with its concomitant satisfactions on an imaginary level in order to be able to continue living.
2. Severe disturbances in interpersonal relationships are apt to produce intense anxiety. Once the threshold of frustration tolerance is passed the patient becomes maladapted, is further frustrated and thus a vicious circle is set up that leads to a schizophrenic breakdown.

3. The individual lives at first according to the pleasure principle, is narcissistic and believes in the omnipotence of his self. The external reality, experience, education and social forces oblige a person to adopt the reality principle and with it societal standards and the introjection of those standards. If this fails, anxiety arises, and escape mechanisms are arranged. Reality is evaded. This failure is compensated for by phantasy life on an infantile level.

\section{Aetiology}

I. Heredity. Ruedin and Kraepelin found family histories of mental illness frequent: around 50 per cent. of cases, with direct inheritance in about 30 per cent. Kallmann calculates probabilities for developing schizophrenia for the relatives of schizophrenics thus: 16 per cent. for children, 12 per cent. for siblings, 8 per cent. for half-sibs, 4 per cent. for grandchildren. There are many more schizoid personalities and 'odd ' people in the families of schizophrenics. The mode of inheritance appears to be either recessive or more probably multi-factorial.

2. Constitution. Mott postulated an 'inborn lack of vitality,' Kretschmer dysplastic, asthenic (leptosomatic) and athletic types in this order. Neurosis and immaturity in parents have been incriminated as evidence for an unstable constitution or predisposition to psychosis in children. Shy, retiring, day-dreaming, "neurotic' children have been found to contribute more than their share to the incidence of schizophrenia. Here, as in the family history and social environment assessments, it is difficult to evaluate whether we are dealing with early symptoms or predisposing factors.

3. Environment. The following have been frequently found in the family histories of schizophrenics: restricted social life, fussing and overprotection, domineering parents, especially mothers, unstable parents, friction between parents, early loss of one parent.

4. Age, in so far as the majority of attacks happen before the age of 30 , but paranoids are usually older, and first attacks of schizophrenia in old age are not uncommon, although often unrecognized owing to overlay by dementia, etc.

5. Precipitating factors are rarely conclusively proved, except occasionally war experiences, accidents, puerperium and, rarely, pregnancy, act as precipitants. 


\section{Prognosis}

Always doubtful, very poor in puerperal schizophrenia, poor in simple and hebephrenic forms, which end usually in dementia, not quite so poor in the other forms, which oftener remit without too much scarring, and best in schizophrenic 'reactions' to shock and toxi-infective insults. Body type is said to have its bearing on prognosis, the best obtaining with pyknics, then athletics. It is usually said that the more acute the disease the better is the prognosis. This means probably that the more obvious and rapidly developing cases come to early treatment, which is important, as the chances of recovery seem to be inversely proportional to the time that has elapsed since onset of symptoms.

\section{Treatment}

I. The majority of psychiatrists think deep insulin coma treatment the treatment of choice. All shock treatments act probably through induced anoxia and stress (in Selye's sense). A course of 40-50 comas, not merely hypoglycaemias, is to be considered a full one, often this has to be repeated.

2. Electro-convulsive therapy is often indicated before, during or after coma treatment. And seems especially during coma treatment (in sopor, which is then interrupted) to make the patient more responsive to insulin treatment. It also serves to interrupt katatonic states, lethargy is diminished, and the patient's general health seems to improve. Full courses of 20-25 convulsions are imperative. ECT alone should not be relied on. The remission rate seems to be well over 50 per cent., but relapses are also more likely. On the whole, there seems to be a definite gain in permanent remissions and in time spent at hospital when insulin coma and ECT are combined.

3. Electronarcosis occasionally is effective when the other two methods have failed.

4. Metrazol shock has been claimed to be more effective than ECT in breaking states of excitement.

5. Leucotomy and similar surgical measures are indicated to relieve tension in otherwise unresponsive or relapsing cases. Except for making nursing easier pre-frontal leucotomy is really promising only in cases in which the personality is fairly well preserved, in the presence of depressive components, and only at an early date, when the patient has not responded to two or three courses of insulin coma and ECT and not too long after one or at the most two years have elapsed since onset. But rarely are we courageous enough to do this.

6. Modified insulin courses are useless, they may only mask the seriousness of the condition.
7. Other treatments have been employe usually with little permanent benefit considering the normal remission rate of 20 to 40 per cens They include pyrotherapy, bloodletting and trans? fusion, withdrawal of cerebro-spinal fluid, unspecific protein shocks, sulphur shocks, acety choline shocks and malononitrile injections. Qf greatest importance are rehabilitation measures during and especially after treatment : occupationa relaxational therapy, group psychotherapy, socian clubs, physical training, etc. Associated with this is the "total push" approach, in which physician takes charge of a small group of patients and makes them engage in all sorts of activities, including outings, and he may or may not indulgg in psychoanalytic interpretations.

8. A few psychiatrists and psychologists mako great claims for psychotherapy, usually analytica fo $_{0}$ This is, however, so prolonged, costly and uncers tain that it can hardly be recommended, at least not before the physical therapies have had a fult trial. Psychotherapy depends on the ability of the patient to co-operate, to form rapport, and sense of suffering is essential. All these arê. usually absent in schizophrenics. The book by M. A. Sechehaye, 'Symbolic Realization,' is however, worth reading as a record of a successful course of analytical treatment of a schizophreficis girl.

\section{Diagnosis}

An exact history is essential. Early adjustmen family history, work record-frequent and uno motivated change of jobs-sudden sexual malo adjustment, general change of personality: shy ness, retiring disposition, moodiness, fatigue, los? of interest, 'queerness' and the grosser symptomsare all significant but not pathognomonic.

Signs and symptoms have been listed, whic establish the diagnosis. Such lists may, of course prove helpful. But on principle schizophrenia is: a disturbance of the total personality. Its early. insidious symptoms may conceal that they come from a deranged person. Curran and Guttman (1949) clinch this by suggesting that, provided the examiner is not schizophrenic, the patient is probably this if after a lengthy conversation the discussion of the problem has not led to some advance at least in understanding it. This is \$ sign of early thought disorder. This sort of approach is useful but still too vague. In spite of our reverence for the total approach, we neef్ to look for more tangible guidance. Disregarding the as yet barely suggestive changes of metabolic structural features and various physico-chemical approaches, oxymetry, capillary microscopy, the solution of the problem lies in an entirely psychological approach, such as in the search for refinedo 
but more or less easily applied examination methods in the psychiatric interview. This is not to belittle the genetic, historical and other approaches, which all have their important places in diagnosis.

If we go through a list of symptoms and signs we have to ask ourselves: ' Firstly, is there any one sign or symptom that is pathognomonic for schizophrenia in the multiplicity of schizophrenic reactions, or several such signs or symptoms in conjunction, and secondly, what examination or refinement of examination procedure can we rely on to elicit such signs or symptoms, if present ?'

In the absence of a cluster of such signs and symptoms as catatonic, paranoid, delusional, hallucinatory, affective phenomena, behaviour disorder, 'odd,' anti- and a-social traits, ideas of passivity, influence, depersonalization and dereization feelings- which may singly all grow out of other than the schizophrenic soil-we are left with the sign of thought disorder. This occurs also in organic states, but is easily recognized as such by other objective physical signs and symptoms. It is therefore of utmost importance and practically pathognomonic for schizophrenia, if permanently present.

Slightest degrees of thought disorder rarely lead to hospitalization. Other more dramatic symptoms and signs will attract attention before the emergence of blatant thought disorder, when the patient begins to talk; what is to the untrained observer arrant nonsense. Our efforts will be primarily directed in the more obscure case toward the uncovery of slight degrees of thought disorder, especially in the allegedly hysterical, obsessional, psychopathic or depressed individual; we shall thus almost invariably be able to clinch the diagnosis.

If schizophrenia is conceived as a hyponoic reaction-combined almost regularly with some catathymic features in Kretschmer's (1934) sense, we shall expect and encounter a loosening of the associative bonds between the constituent parts of the thought processes, concretistic thinking and similar phenomena.

Thought disorder can almost always be demonstrated, if necessary by the employment of certain techniques. It is not easily concealed like many symptoms. It is a (objective) sign. It is, in isolation, not pathognomonic for schizophrenia, but for a hyponoic reaction, the most frequent, permanent and progressive of which is schizophrenia. Hysterical dreamlike states, panicreactions and dementia, etc., are easily excluded by their other features.

\section{A note on Childhood Schizophrenia}

In childhood schizophrenia are found: with- drawal, loss of affect, catatonia, deterioration of habits; in dementia praecocissima: depression, affective poverty, autism and phonographism (in both there may be mutism); in dementia infantilis : rapid impairment of speech, until only some phrases remain; in hyperkinetic disease: aimless hyperkinesis, moodiness and negativism. In all there is severe restriction of interests. Probably a good number of ' mental defectives' are endproducts of a child schizophrenia. Early diagnosis may be difficult development; a full history is of paramount importance. Some difficulties of diagnosis are discussed in Salfield (1950) and Salfield and Greenland (1953).

\section{Extension of the Psychiatric Examination for the Discovery of Thought Disorder}

Vigotzky's findings of disturbance of conceptual thinking replaced by $a$ regression to complex-thinking have been confirmed by Hanfmann and Kasanin (1942); and Goldstein (1943) stresses concretistic thought changes in schizophrenia. Hall (r95 I) finds, in keeping with such ' simplification of thinking,' that schizophrenics think in differences rather than similarities-as can also be observed in children. The interpretation of proverbs often shows up minor degrees of thought disorder and brings out irrelevances (Hall, 195I). The more informal use of the Vigotzky (synonym: Hanfmann-Kasanin) test shows the presence of impairment of concept formation (Rapaport, 1945). A knowledge of the meaning of scatter in some psychometric tests like the Wechsler-Bellevue test is valuable (cp. Rapaport, 1945). The most valuable tool is in the opinion of many the Rorschach inkblot test (cp. Klopfer and Kelley, 1946, and Rapaport, 1945). These few references may provide a background for our contentions.

In the Rorschach test certain signs are indicative of schizophrenic changes (cp. e.g. Zucker, 1952, and Young, 1948). In our opinion they are all due to the above described features of thought disorder or fluctuation in the quality of concept formation. We find, singly or in combination, fluctuation of form level, i.e. unpredictability of quality, telescoping of ideas, that are often incongruous, into one concept, confabulation, irrelevancy, illogicality, far-fetched responses, perseveration in all degrees, confusion and bizarrerie.

We may regard psychological tests as standardzied situations in which behaviour, including verbalizations, can be comparatively studied. By analogy and empirical correlation of test behaviour with otherwise observable behaviour we can arrive at so-called interpretations, the validity of which varies proportionally with the representativeness, accuracy and mode of evaluation of behaviour 
observations, both in the test situation and in other standardized or unstandardized situations. We have to enquire, therefore, into the quality uf those situations and their given conditions, when we evaluate test results. We must ask, for instance, ' in what internal and external milieus would presumably any individual behave in the given manner?'

How far such an appreciation can be 'objective,' or we may prefer the term 'inter-subjective,' is still, and some believe it will remain, extremely doubtful. But this does not invalidate the procedure, as an examination takes place between individuals, and is thus ' subjective.'

Klopfer and Kelley (1946) hesitate to claim for the Rorschach test, that well tried and most thoroughly investigated tool, powers that surpass the unaided approach. They say: 'If no definite personality changes have been produced no change in the Rorschach test can appear.' But for the Rorschach test is true, as mutatis mutandis for other tests, what Rapaport (1945) predicates for the Vigotzky test, viz. that "its difficulty puts the subject's thinking to task and may elicit deeplying and diagnostically significant features of his thought organization, whereas in everyday life, where one treads on well-known ground, verbal convention and apparent meaning can well obscure or prevent from coming to expression such pathological trends in thinking.' In all these and other tests, bizarre and other obviously disordered reactions are often obtained.

These few remarks are not exhaustive nor have the only useful tests been mentioned. One of the main purposes of this paper is to show that with a few relatively simple means much can be achieved. The following four case histories aim at illustrating the integration of clinical observation with simple psychological testing and deductions derived therefrom, so that an unequivocal diagnosis can be arrived at.

CASE I.-A man of 2I, a storekeeper. No physical abnormalities. Family history negative. The eldest of three siblings and three halfsiblings. His mother died when he was 4. Excepting the last two months he has not been getting on well with his stepmother. His childhood was not very happy. He always felt he did not receive the love and attention due to him. He felt frustrated, bit his nails, and has always been very critical of his stepmother. During the war he was evacuated for three years and liked it perhaps too much. His school record is on all counts normal. He has many interests: music, sports and the pictures, but he does not dance and restricts his reading to newspapers. He fell downstairs when a child and since then he said he had squinted till operated for this five years ago.
His work record is good. Sexually there are no abnormalities, he masturbated from 15 to 18 years of age; then he has had girl friends, lately a steady one. But although he should like to have sexual 은 intercourse he has not had any. He served in the army for two years, 1947-49. He resented being $\stackrel{\vec{D}}{\overrightarrow{0}}$ bossed and felt unappreciated and deprived of his chance for self-development.

In the autumn of r949, during manoeuvres, he $\frac{\overline{\bar{s}}}{\bar{D}}$ sweated very much and, he said, his hair came $\mathbb{\Phi}$ out in bunches. Subsequently he 'forgot all about it,' but in July $195^{\circ}$ the trouble started ${ }^{\text {s }}$ again, and he became more and more concerned $\vec{O}$ and worried about it. After consulting his doctor $\overrightarrow{\vec{H}}$ and a dermatologist, he was referred to the ${ }_{\sigma}$ psychiatric clinic, as he felt he could not go on w orking.

On examination he was found to be a good-i looking young man with fair hair of average thick- $\frac{0}{\omega}$ ness and distribution. There were no signs of his hair thinning or coming out on combing. He $\underset{\omega}{\omega}$ was friendly, pleasantly mannered and co-operative $ᄋ$ in the ward. He appeared somewhat diffident and 0 anxious, introspective, uncertain of himself and a great doubter. There were no signs of depression, $\subset$ retardation or poverty of ideas. $\mathrm{He}$ was of $\underset{\mathbb{D}}{\rightleftharpoons}$ average intelligence with a good command of lan- $\vec{D}$ guage, well informed and unexpectedly knowledge of able in a great many subjects. Memory, attentio $\omega$ and concentration as well as thought processes appeared unimpaired. There are no hallucin $\%$ tions, delusions, depersonalization symptoms other than the one described. He is a stickler for order and, he said, gets worried if things are not 'just $\stackrel{\square}{\triangle}$ so.' ' If you do a thing, why not do it properly ? ' $\overrightarrow{\vec{P}}$ He described himself as sensitive and very vain. $\frac{}{3}$ He says he has a miserable nature and is dull and unhappy. He had been so since childhood, but: loves life. He feels no loss of energy, but feels cold and has no feeling for other people, though 3 . he 'would share his last cigarette.' The differential diagnosis is between an obsessional and a schizophrenic reaction. The last-mentioned 8 feeling may point to a very mild depersonalization, $₹$ but is too vague. His personality is narcissistic o and obsessional. But there is no evidence of $a_{>}$ schizophrenic process. But, as Gordon (1950)을. has pointed out, obsessions may 'turn into delusions,' or, better perhaps, there is no dif- $\mathrm{N}$ ferentiating between early delusions of certain 0 types and obsessions. The only hypoboulic trace is his so very normal incapacity to concentrate on disagreeable tasks. There are no hyponoic mechanisms, but he treats himself in a way typical of Kretschmer's (1934) sensitives. He has $\stackrel{\oplus}{\rightarrow}$ some intellectual insight into his symptom, although this does not influence his behaviour. We are dealing with a catathymic reaction. The $\mathbb{D}$ 
evidence seems to point to a schizoid personality, but does not explain the symptom.

He had a short period of superficial psychotherapy, during which I took the following line, which he fully accepted. Because of his feeling of being rejected in earlier youth, as both his mother died and her substitute appeared to neglect him, he became regressively and defensively narcissistic. His vanity, represented by his hair, was his strength and masculinity. His fears of emotional defeat with regard to his stepmother, who is apprehended as the bad mother, is symbolized by the imaginarily falling out hair. This Samson complex may be a symptom of ultimately positive or negative value: was he merely losing the battle against an artificial fear, or was he giving up his isolation by renouncing this spurious strength?

After five weeks he suddenly feels full of confidence, is about to resume his work and leaves hospital.

Taking due note of his first 'forgetting all about' his symptom, I do not flatter myself that his change for the better was due to psychotherapy. It looks rather like a spontaneous remission of a schizophrenic or obsessional episode.

If we turn now to the evidence furnished by the Rorschach record, the picture becomes clearer: there are no conclusive signs for open anxiety or hysteria. There is colour shock coupled with colour avoidance and extreme shading shock, both of which are again not conclusive as to the presence of neurotic versus psychotic disorder. There are two anatomy responses pointing to preoccupation with the body. There are only eight responses plus six additionals (on prodding). There are four human movement responses. There is a suggestion of impotence and perseveration and the anatomy responses are both $\mathbf{F k}$ - This in combination with rejection of Cards V, IX and $\mathrm{X}$, both in view of the number of rejections and the typical rejection of Card V, makes the diagnosis of a paranoid schizophrenia probable if not certain. The record was probably obtained when the obsessional defences against an underlying psychosis had temporarily broken down. The prognosis becomes accordingly poorer, although, as Stengel (1945) points out, complete fragmentation of the personality is less likely in schizophrenics presenting strong obsessional tendencies.

CASE 2.-A man of 45. Complained of frequency of micturition, that only a few drops are expelled at each attempt and of pain in the region of the bladder, sometimes also in the penis and left testicle. The pain radiates over the back and into the rectum, also into the chest. He complains of buzzing in the ears. There is a high degree of myopia, some chronic bronchitis and clinical evidence of hyperthyroidism with slight exophthalmos and slight but hard, smooth enlargement of the gland.

There are no abnormalities in the family and childhood histories. There is a degree of sexual maladjustment. He admits to practising coitus interruptus and experiencing a lessening of libido and potency.

Ten years ago he was compensated for miners' nystagmus, of which there is no trace now. During the war he injured a costal cartilage, for which he was operated on. A fistula resulted and persisted for some time. He developed pain in the left iliac fossa. This pain wandered at times practically all over the abdomen and elsewhere. $\mathrm{He}$ was repeatedly investigated, but there were no positive findings explaining his complaint.

Patient is eager, emphatic, tense, wrapped up in his complaints, and punctuates their recital by gestures. His face is drawn and he stresses again and again that he is "telling the truth. No use not telling the doctor the truth.' $\mathrm{He}$ is querulous and petulant, but says that he feels cheerful and energetic apart from his complaint. There were no decisive depressive or other psychotic features? and no characteristic changes of intellect or affect. The provisional diagnosis was, for lack of bettere hypochondriasis on a schizophrenic or hysterical basis.

The Rorschach test, not performed by myself, was reported to reveal a 'clearly not neurotic picture, no evidence of hysteria; there were five sex responses and one fabulated response, a trace of obsessional characteristics and a tendency to perseveration. Probable diagnosis: paranoid schizophrenia in an obsessional personality.' Equally, the Wechsler Bellevue test was reported to reveal: ' Verbal I.Q. I03, Performance I.Q. 83. Morbid scatter. Picture arrangement no score. Object assembly 3. Blocking on digit symbol test. Queer verbalizations on picture arrangement and picture completion tests. Diagnosis fits paranoid schizophrenia.'

At the time without knowledge of these results I administered among other tests, the Vigotzky test, over which patient spent almost one hour. It is unnecessary to score it formally. This is the protocol:

When seeing the blocks he looks dumbfounded. He first sorts according to colours, adding one red block to each group but retains one blue block in the yellow group. Asked for the principle of the arrangement he says: "Two fives and two sixes. Is there a snag ?' $\mathrm{He}$ is given a clue and builds towers with the blocks. $\mathrm{He}$ is told 
not to do that, and thereupon builds patterns and again towers. He says: 'It's a kind of sphinx or historic place, like the place we live in. It's a hotel, a pub. It represents the pub, a pub like the " Stag," it's 100 years of age."

In the following he reverts to colour sorting, puzzles over the nonsense syllable on the back of the blocks, and it is impossible to make him see that the colour sorting is not the required solution. He comes back to the nonsense syllable and mumbles, that if only he knew the meaning of the word . . . it's just guess work . . . it's a matter of luck. And when all the blocks are turned up for him and sorted into the four 'families' he pronounces gravely that they belong together because they have the same name. And when given the correct concept, he still makes a mistake on resorting. There is therefore definite impairment of concept formation, rigidity, suspicion and thought disorder in the form of sudden outbursts of hyponoic thought. This observation by itself points to the possibility of paranoid schizophrenia; and supported by the other quoted reports makes the diagnosis almost certain. It is to be stressed that no thought disorder was elicited in the repeated clinical examinations.

CASE 3.-A married woman of 40. No physical abnormalities. She complains of terrible headaches, depression, fear of something unknown, palpitations, tremor, vomiting and seeing silver stripes before her eyes, especially when vomiting.

The following is the abridged assessment by a colleague under whose care she had been for some time: 'She nurses a strong grievance against her mother for sending her to an orphanage at the age of 12, when her father died. She appears - affected in manner and speech, evasive and detached, wept briefly once without obvious reason; is apathetic, without tenseness or surface anxiety but has to be reassured. Diagnosis: anxiety state in a schizoid personality.' She was given several narco-explorations, numerous interviews, and another colleague diagnosed an atypical depressive state.

I saw her two months after her original admission and my impression was briefly: 'She is completely chaotic; her thinking is scattered. There is deep anxiety, bewilderment, panic. She finds it difficult to establish contact. She is theatrically manneristic. She has profound hate feelings against her husband. She hesitantly denies delusions and hallucinations. Her emotions, though dramatic, are shallow.'

Subsequently she was given the Rorschach test, during which she was completely uncontrolled and uncontrollable. There were 18 responses, 3 rejections, characteristically including Card V. There was colour and shading shock, sudden deterioration of form level, impotence, perplexity as well as di responses, one FC'-.? Constriction. Anxiety. To Card IX she responded $\stackrel{\propto}{\Omega}$ with: ' $\mathrm{Oh}$, oh, oh, what horrible face-she looksc. away-why doesn't it go ?-still looking away.' Asked where the face is, she says: 'No, not on $\frac{\text { ? }}{+}$ the card.' Diagnosis: schizophrenia, mainly para-음 noid. It will be noted again that the hallucination $\frac{\overline{\bar{S}}}{\overline{\mathrm{n}}}$ and the schizophrenic syndrome as seen in the Rorschach had not been clinically clinched but $\stackrel{\Phi}{\circ}$ was elicited by the test.

After a subsequent course of six ECT treat- $\rightarrow$ ments, two per day, she improved. She left a fortnight later and was assessed by another colleague $\vec{\omega}$ on discharge: improvement maintained. Stillo requires night sedation which she had neededo for years. Cheerful, but elation passed, has $\underline{\exists}$. realistic attitude to life, domestic matters and ic self now. Seems very much less self-centred $\omega_{్}$ and more tolerant to people and life.

Because of the success of ECT critics may support the atypical depression diagnosis. But history, clinical picture and test performance? do not support this. If, however, we under- $\vec{c}$ stand tests as standardized behaviour, as has $\subsetneq$ been urged above, the resistance to accept the $\widehat{D}$ diagnosis on this basis should vanish. If she $\overrightarrow{0}$ had behaved in the clinical interview as spe behaved during the test, there would not have been any doubt in any psychiatrist's mind whet the diagnosis should have been. Her clinical picture fits those descriptions, criticized above, given by Hoch and Polatin as pseudo-neurotic $\frac{\not}{\mathrm{D}}$ forms of schizophrenia, viz. autistic, dereistic, $\varrho$ withdrawn, diffuse ambivalent to aims, adaptation, $\overrightarrow{\overrightarrow{0}}$ some inappropriateness of emotional response, 3 pan-anxiety, tension, conversion, vegetative signs, phobias, obsessions and compulsions, anhedonia, absence of gross thought disorder and catathymic $\frac{\partial}{3}$ reactions. Many of these symptoms are obvious in this patient; if thought of as a syndrome, they become obviously schizophrenic.

CASE 4.-A girl of 19 complains of not feeling real and having a continual vision. Her maternal aunt had ' religious mania' and ' was taken away.'음 Her mother, as I experienced myself, is highly $\rightarrow$ strung, impulsive, opinionated and impervious to․ㅡ․ reasoning. She has a duodenal ulcer. Father was N divorced from mother when patient was $4 . \mathrm{He}_{\mathrm{N}}^{\mathrm{N}}$ was Roman Catholic by religion, the mother is 0 not. This gave rise to many frictions. He was a violent man, given to drinking. The stepfather is quiet and friendly, an 'atheist.' A brother iso quiet, shy and apparently not very bright, and young half-brothers are well.

Patient recalls her father as a ' bad man.' The parents never got on well. Although the step- $\frac{\text { Oे }}{\mathbb{D}}$ father, whom mother married two years later, is $\frac{\mathbb{Q}}{\mathbb{Q}}$ 
pleasant, and home life was quite good since mother's re-marriage. Patient described her childhood as unhappy and herself as melancholy. - Mother returned one day from work and found me in tears. Evidently my father, a brutal man, had been hitting me with a leather belt. A fight then ensued between them, in which my mother, as usual, came off worst. I always regarded my father with fear and I loved my mother intensely: Though always being a reserved person, I did not show it. I used to be frightened for her when my father was in a violent temper. One day my mother sent me upstairs to get a dress from the wardrobe. I was halfway up when I beheld my father hanging across the banister. $\mathrm{He}$ was merely trying to frighten my mother into believing he was trying to commit suicide, instead he reduced me to a state of hysteria. My mother had to put my feet into hot water to try and quieten me. My father used to try and turn me against my mother by saying: "Don't go near her, she's the devil." One night my father was in a particularly evil mood. He fought my mother until he knocked out two of her teeth and kicked her until she could hardly crawl. My aunt happened to come in at this moment; she took one look at my mother and went for a policeman immediately.'

At school she got on quite well. But she did not like school very much. She always kept to herself and did not make many friends during that time. She gained promotion to secondary school but left before I $_{5}$, because she did not like school. She drifted then into an usherette job, she thought this unwise and would have preferred an office job. She disliked nightwork. But she stayed for two years. Again she drifted into another usherette job and stayed for another year. When 17 she became a shop assistant, where she still is. She is in charge of a counter and has a responsible job, but earns under $£ 3$ per week. She does not realize that this is little remuneration for the post.

Her interests are dancing and reading novels. Sexually she is quite normal, but her feelings are somewhat disorganized. Menses started at 16. She was not unprepared for them. She has had some flirtations before the present 'steady' boy friend. She thinks she loves him and he her. She intended to marry but seriously thought of calling it all off on account of her present disorder. She has been somewhat frightened at the idea of marrying. She has marked ideas of feminine inferiority. She talks of 'submitting' to sexual intercourse and that 'men are more made for sex.' She would think it wrong to have intercourse before marriage, but indulges in ' petting.' She hesitantly admits that she is still in love perhaps with a former boy friend, who is now otherwise engaged and jilted her and who is, according to mother, ' a bounder.' $\mathrm{He}$ tried to seduce her. He was ' glamorous,' but the present one is 'steady.' She feels reluctantly that he is the one who is in love. With the former it was the other way round. She expresses snobbish social ideas. She and the family are a cut above the neighbourhood, although they live in pretty slummish conditions. They correct each other's grammar, and poor John-i.e. the boy friendcannot spell and talk correctly.

She had no special significant diseases, but three years ago she had a 'breakdown' lasting for a few days. She had then 'guilt feelings'; she cannot specify their nature, but she recovered after a few days' holiday.

She described herself as always shy, retiring and diffident. She wants to be happy but cannot be so. She feels affectionate but cannot give expression to it. She feels there is an obstacle to her feeling as other people do. She feels ill and that something is amiss. She feels hopeless about it and that she might never be better. She is depressed and has often felt like doing away with herself, but would not do it on account of her family and friends.

She is quiet and restrained, but open and frank $\vec{c}$ and a willing informer. She speaks in a quieto $c$ and quite educated voice. She is coherent and logical. There are no signs of thought disorder? blocking or the like. There are no delusions, feelings of reference or influence. She appears, in conversation, of above average intelligence. There is no impairment of attention, memory or other intellectual functions, but apart from the feeling of depression, there is an acute feeling of depersonalization and a 'vision' to be accounted for.

A few weeks ago a woman of the neighbourhood called at the house and talked at length about a case of suicide. She was then left alone in the house and began to ruminate. She thought that people did not think of God often enough, and this became an imperative idea. She has had since then the "vision' of a white garbed figure who she thinks is God. This is, however, an evil figure. This figure is in her mind, she says, obtrudes itself continuously and she has no control over it, but it is not in the visual space and does not superimpose itself on the outside world nor is it, as it were, transparent. She apperceives it as imagery. She is afraid of this. She does not feel herself as real. She has changed in a bad way. She cannot comprehend herself. Other people appear unreal and she feels she cannot establish emotional contact with them since the incident. She keeps dreaming of 
herself as she used to be, and, astonishingly, she describes herself in this context as formerly a happy girl. Besides she also had a series of three dreams: her present boy friend dies of a blistering skin disease; second dream: he fails to fetch her from home; third dream: he fails to fetch her from work; fourth dream: she goes to a dance, he is there but takes no notice of her and keeps entirely to himself. It is superfluous here to go into the interpretations, but this material shows her profound ambivalence to the father figures which expresses itself in her attitudes to her father, stepfather and the ambivalent figure of God. This may well have been influencing her attitude to her boy friends. Her personality make-up, a certain oddity of her attitudes to father and boy friends, and last not least, her depersonalization in conjunction with what appears to be a pseudo-hallucination but is not quite certainly that, the hereditary factors and her early history all suggest the possibility of a schizophrenic reaction. She believes she is schizophrenic and was diagnosed as such at first by another psychiatrist and gave that impression to myself at first.

She was therefore given the Vigotzky and the Rorschach tests and a number of proverbs to be interpreted, as well as the progressive matrices.

The Rorschach test showed impaired intellectual functioning, constriction of feeling, a fantastic approach to reality, an immature personality with suppression of human movement responses, probably pointing to poverty of empathy and human relations; furthermore, tension, anxiety and sensitiveness, with some depressive trends. There was one mild lapse in form level and a tendency to fabulation. The label would be: general immaturity with some anxiety and depression. No signs of a schizophrenic process.

In the matrices she came out Grade IV with considerable scatter, which made the results unreliable. Time 19 minutes, individual administration. She was given the test a second time and left to do it by herself. She took almost one hour over it and scored Grade III, with much less scatter. This seems to indicate temporary inefficiency in the presence of people.

She interpreted the proverbs as follows:

I. You cannot make a silk purse out of a sow's ear: You cannot make anything refined if a person is born rough.

2. A drowning man catches at a straw: In a last desperate effort to save himself, he does not want to drown, he regrets it. This shows some catathymic influences with depression.

3. A bird in the hand is worth two in the bush: Make do with what you've got than strive for what is out of your reach.
4. Not all is gold that glitters: Bright things in life are not really worth while-the glitter may 으 not be worth anything. The same remark as for No. 2 applies here, though perhaps less so.

5. A stitch in time saves nine: If you see a $\stackrel{c}{.}$ mistake in the beginning repair it before it gets larger.

6. The early bird catches the worm: An alert person is always on the look-out for everything, gets the job done better than the lazy who has not her wits about her.

There is certainly no schizophrenic thought ${ }^{\circ}$ disorder to be found in these interpretations.

Vigotzki test:

I. She is given one clue, makes five groups, $\vec{\omega}$ then puts squares with triangles, because ' they are sections of squares.' Cannot decide whether to put triangles with squares or trapezes.

2. Two clues given: She 'measures sizes' as है ' they could be cut out of each other.' Has no plan of action.

3. Three clues given. No solution attempted.

4. Four clues given. No solution attempted.

5. Two of each of the four classes turned up. ' I'm going by depth.' But then she confounds widths. Starts again sorting according to shapes, but puts the low ones with high ones indiscriminately, because of ' sizes.'

6. All blocks turned up. 'Do they all go inte a pattern ?' She cannot find any explanation for. the groupings. Her behaviour is rigid and, at the same time, confused; she returns to discarded solutions. She arranges blocks into "pretty patterns.' Concept formation is seriously impaired, but is not bizarre. It is quite possibly due to impaired intellectual functions through anxiety and inattention. A certain degree of compulsiveness is obvious.

She had one ether abreaction and one sodium amytal session with no improvement or new material appearing. She gave notice to leave against advice. It was planned to give her a series of ECTs, as her disorder is probably basically depressive. She was advised that she is not schizophrenic, that she would probably recover spontaneously within a year or two, that relapses are likely, but that no personality deterioration was to be anticipated.

\section{Summary}

The diagnosis of some forms and stages of $N$ schizophrenia may prove difficult. Schizophrenia $\omega$ cannot be diagnosed unless a syndrome of signs and symptoms occurs that includes hyponoic $\stackrel{O}{=}$ reactions. Most signs and symptoms are fairly obvious except early thought disorder. Its detection becomes, therefore, imperative. The discovery of slightest degrees of thought disorder 
often requires the use of special techniques. Some of these are shortly discussed and their use demonstrated by case histories. It is believed that it is desirable to avoid terms like 'pseudo' schizophrenia as nothing is gained by their use, but much may be lost if such terms are allowed to obscure the psychiatrist's judgment as to the institution of suitable treatment and the correct prognosis, which depend both on the correct diagnosis.

\section{GLOSSARY}

of terms, in order of their first occurrence in this paper, that may be unfamiliar to the non-psychiatrist.

Archetypes-innate facilitations of stereotyped apperceptions, as they arise as images from the unconscious, e.g. in dreams.

Depersonalization and dereization-feelings that one's self or the external world have changed or are incomprehensible; related to un-reality feelings; nihilistic delusions (all or some things do not exist); passivity feelings and feelings of influence are delusional, i.e. thought-conditioned, the former are affective.

The pleasure and the reality principles are, according to Freud, stages of development, during which the gaining of pleasure and the stringency of the real (external) world are the regulators of behaviour, respectively.

Hyponoic-functioning on a level lower than normal, of consciousness, such as occurring in dreams, hypnosis and hysterical states.

Catathymic - thinking which is influenced and distorted by affect.

Concretistic thinking - thinking in concrete rather than abstract terms.

Autism-living in phantasy uncorrected by reality.

Phonographism-repetitive and imitative speech.

Projective tests-more or less meaningless test material evoking responses by patient projecting his own mind's contents into them.

Complex thinking - thinking determined by unconscious autonomous complexes, i.e. clusters of ideas, etc., not subject to the ego's control.

Vigotzky test-blocks of different shapes, colours, heights and widths that are to be grouped in consistent groups.

Rorschach test-a projective test, consisting of partly coloured blots. The responses are scored according to how much and what parts of the blots are used, how much of form, colour, ' movement,' ' texture,' etc., enters the responses, and the kind of contents. From these and other factors, like reaction times, sequence of responses, and behaviour during the tests, valuable personality assessments can be formulated.

\section{BIBLIOGRAPHY}

BLEULER, E. (1930), ' Lehrbuch der Psychiatrie,' Springer, Berlin. BLEULER, M. (1931), Arch. Neurol. Psychiat., 26. COHEN, M. (1949), Arch. Ophth., 4I.

CURRAN, D,' and GUTTMANN, E. (1949), 'Psychological Medicine,' Livingstone, Edinburgh.

FREUD, S. (1924), 'Collected Papers,' Vol. I, Internat. Psychoanal. Press, New York.

FREUD, S. (1925), ' Collected Papers,' Vol. III, Hogarth, London. GOLDSTEIN, K. (1943), F. Nerv. Ment. Dis., 97, 26 I.

GORDON, A. (1950), Am. F. Psychiat., 107, 455.

HALL, K. R. L. (1951), Brit. F. med. Psychol., 24, 118.

HANFMAN, E., and KASANIN, J. S. (1942), 'Conceptual Thinking in Schizophrenia,' Nerv. Diseases Monograph No. 68, New York.

HOCH P., and POLATIN, P. (1949), Psychiatric. Quart., 23, 248. JASPERS, K. (1948), 'Allgemeine Psychopathologie,' Springer, Heidelberg.

JUNG C G. (1936), Nerv. Ment. Diseases Monograph No. 3.

KALLMANN, F. (1938), 'The Genetics of Schizophrenia,' Augustin, New York.

KLOPFER, B., and KELLEY, D. MCG. (1946 ' The Rorschach), Technique,' World Book Co., New York.

KRAEPELIN, E. (1 909), Psychiatrie, Barth., Leipzig.

KRETSCHMER, E. (1934), 'A Textbook of Medical Psychology,' Oxford Medical Publications, London.

LANGFELDT, G. (r951), Am. F. Psychiat., 108, 123.

MACE, N. C., KOFF, S. A., CHILNEK, I., and GARFIELD, S. L. (1949), Ұ. Nerv. Ment. Dis., 110, 336.

MAYER-GROSS, W. (1952), f. Ment. Sc., 98, 413.

MEDUNA, L. J., and MCCULLOCH, W. S. (1945), Med. Clin. North America, 29, 147.

MOTT, F. (1926), Proc. Roy. Soc. Med., 12, 1920.

PIOUS, W. L. (1950), Psychoanal. Quart., 19, 327.

RAPAPORT, D. (1945), 'Diagnostic Psychological Testing,' 2 vols., Year Book Publishers, Chicago.

RUEDIN, E. (I9I6), ' Zur Vererbung Neuentstchung der Dementia Precox,' Springer, Berlin.

SALFIELD, D. J., and GREENLAND, C. (1953), 'Stories and Drawings.' 'To be published.

SALFIELD, D. J. (1950), F. Ment. Sc., 96, 405.

SECHEHAYE, M. A. (1949), Arch. Ophth., 4I.

STENGEL, E. (1945), f. Ment. Sc., 91, 166.

YOUNG, R. J. (1948), Am. F. Psychiat., 105, 381.

VIGOTZKY, L. (1934), Arch. Neurol. Psychiat., 31.

ZAIDENS, S. H. (1950), Psychosom Med., 12, 250.

ZUCKER, L. (1952), Am F. Psychother., 6, 44.

\section{HOW TO GET THERE}

An Address Book for the Medical profession, showing how to reach the various Colleges, Societies, Institutes and Hospitals in and near London.

Third Edition: 1950
FELLOWSHIP OF POSTGRADUATE MEDICINE
60 Portland Place, London, W.I
Price 2s. 6d. 